\title{
El video como proceso de formación reflexiva en la práctica docente universitaria
}

Blanca de la Luz Fernández Heredia ${ }^{1}$ y Edith Jiménez Ríos ${ }^{1}$

\section{Introducción}

En la actualidad, en distintas universidades del país podemos constatar la existencia de profesores sin una formación referente a los aspectos didáctico-pedagógicos. Bain (2007) menciona que los profesores tienen conocimiento de su profesión -lo cual es un requisito básico para impartir clases en el nivel superior-, pero no cuentan, en su mayoría, con una formación pedagógica sobre cómo enseñar en las aulas.

El docente, como parte del proceso educativo, desempeña un papel importante en el diseño y aplicación de un currículum académico. De esta manera, los profesores son aquellos que ejercen una mediación entre el plan de estudios y el alumno, por lo que deben realizar actividades que conlleven a mejorar la calidad de la enseñanza, como: un análisis de la situación de ésta, la proposición crítica de objetivos y metas, así como el establecimiento de cursos y evaluación continua de los resulta-

1 Universidad Michoacana de San Nicolás de Hidalgo. 
dos; no obstante, la realidad actual muestra que la mayoría de los docentes emplea modelos orientados hacia la enseñanza, más que aquellos que podrían identificarse como constructivistas (Aparicio y Pozo, 2006).

Considerando, por otra parte, que la profesión docente es una tarea compleja, que considera el resultado de las representaciones sociales, culturales e ideológicas de un contexto determinado y que están presentes en la actividad del aula, debe considerarse que los docentes no son sólo personas que aplican conocimientos producidos por otros, sino también son quienes asumen la práctica a partir de los significados que ellos mismos le dan, quienes poseen conocimientos y un saber hacer cuyo origen es su propia actividad y a partir de los cuales la estructura y la orienta (Tardif, 2004).

Según Marcelo (2008), es mucho el aprendizaje que una persona que se forma en un programa de licenciatura o de posgrado ha acumulado a lo largo de la vida. Es aquí donde cobra vigencia aquel término acuñado por Donald Schôn (1983) del "profesional reflexivo" en su propósito por descubrir la forma en que los docentes se enfrentan a diversas situaciones que, como la enseñanza, son inciertas, inestables y singulares. De igual manera, Stenhouse (1985) declara que la enseñanza constituye un arte, por cuanto significa la expresión de determinados valores y una determinada búsqueda que se realiza en la propia práctica de la enseñanza, denominando al profesor como un investigador (Contreras, 2001).

\section{Método}

El presente estudio se situó en una metodología cualitativa que toma como referente al sujeto, a lo particular y es de tipo interpretativo. Se eligió este tipo de método porque es conveniente para investigaciones individuales o de pequeños grupos a los que se les indaga sobre su entorno, pidiéndoles profundizar en sus experiencias, expectativas, criterios y significados; es decir, la forma en que los participantes perciben subjetivamente su realidad. 
Los datos que se muestran en este trabajo corresponden a la fase cualitativa de un proyecto de evaluación y formación docente que siguió una metodología de investigación mixta.

\section{Participantes}

En este trabajo de investigación la muestra se seleccionó mediante el método no probabilístico y participaron 8 docentes: 5 mujeres y 3 hombres, de edades comprendidas entre 27 y 45 años de edad que imparten clase en los distintos semestres que conforman el plan de estudios de la Licenciatura en Psicología de la Universidad Michoacana de San Nicolás de Hidalgo, ubicada en la ciudad de Morelia, en el estado de Michoacán, y cuyas materias han sido reportadas como las que tienen mayor índice de reprobación. Algunos de estos profesores son noveles y otros son expertos. La experiencia profesional va desde los tres hasta los veinticinco años de servicio docente.

\section{Material}

Se utilizaron las técnicas de la observación y de la entrevista semiestructurada, así como la videograbación.

Se empleó el análisis de los videos como una forma de autoevaluación de los docentes de la muestra elegida a fin de que ellos mismos pudieran conocer, comprender y reflexionar sobre su práctica docente y contribuir a su mejora. De este modo, el objeto de análisis fue el trabajo de los docentes en el aula, rescatando su experiencia y, sobre todo, el contexto en que ocurre la enseñanza.

La intención fue propiciar que los docentes pudieran crear marcos de referencia a partir de los cuales se pudiera proponer algún aspecto para mejorar y determinar cuál era la estrategia para lograrlo.

\section{Procedimiento}

Primeramente se realizaron las entrevistas con los docentes participantes con la finalidad de conocer cuáles eran los paradigmas 
de enseñanza y de aprendizaje que poseían. Posteriormente se programaron dos videograbaciones durante el desarrollo de sus clases a lo largo el semestre.

Para la revisión y análisis de los videos, los profesores tenían la libertad de detener el avance del video en el momento que lo decidieran; asimismo, podían comentar con el investigador sobre lo que recordaban, sentían, comprendían y pensaban acerca de su actuación en el aula. La observación y análisis de los videos con el profesor participante tuvo una duración aproximada de 60 minutos.

\section{Resultados}

Algunos de los argumentos que dieron los profesores de la muestra elegida respecto a la observación y análisis de la videofilmación, fueron que ellos y ellas consideran que la enseñanza es una actividad que debe planearse, que requiere definir una interacción del profesor con los alumnos y en la que es muy importante que los estudiantes trabajen en equipo, pues esto permite la coevaluación entre ellos, además de que socializan sus aprendizajes. A este respecto, el Docente 8 (D8) comenta:

Pienso que el proceso de enseñanza es poner los conocimientos al muchacho y que le sean significativos para que éste pueda aprender; que el muchacho tenga una disposición para trabajar en equipo y aprender colectivamente. La enseñanza debe tomar conocimientos previos para revolucionarlos y que a partir de los conocimientos que ya trae le ayude a transformarlos y reafirmarlos con los nuevos que está adquiriendo con el apoyo de su grupo.

Para algunos de ellos y ellas, sus principales fortalezas son desarrollar en los estudiantes la capacidad de análisis, la creatividad, así como que sean "ágiles en sus pensamientos, aprendan a preguntar y a polemizar también". El modelo de enseñanza que se asume es aquel que busca llegar a un nivel 
de abstracción tal, que los estudiantes puedan desarrollar niveles complejos de pensamiento y seguir en la idea de que los alumnos tengan una sólida formación, aprendan a innovar y a aprender que como investigadores deben ser profesionales. El D5 realiza la siguiente aportación en este sentido:

Es cuando el alumno tiene los conocimientos pero puede aplicarlos a cualquier situación, es cuando él reconstruye, es cuando puede hacer simuladores, en cuestión mental o en la realidad, y puede aplicar los conocimientos a cualquier situación y puede generar una serie de alternativas; es donde se está dando el proceso de metacognición, llegando a un producto determinado o a varios productos, etcétera.

Algunos profesores consideran que han mejorado en su estilo de enseñanza; sin embargo, hay cosas que aún tienen que mejorar. Generar en los alumnos la duda y el escepticismo es un recurso que permite motivarlos, hacer la clase más dinámica y llevadera. Varios de ellos consideran que su clase es dialogante y se han fijado como meta buscar más actividades en las que los estudiantes participen de manera individual y grupal. El D3 señala:

Todos empleamos muchas estrategias, generalmente cuando se tiene un grupo en donde tienes 2 participativos, 20 rebeldes, otros 10 calladitos, otros cuantos, tienes que utilizar estrategias en donde debes hacer que los muchachos participen, los participativos utilizarlos como pivotes en el grupo, y eso me ha funcionado, en grupos donde hay habilidades diferentes debes emplear a los alumnos que son pilares para que te ayuden a desarrollar una estructura que te apoye en la clase.

A partir del trabajo con estos profesores, es importante que ellos y ellas reconozcan que la actividad de reflexión en la acción adopta características propias de la práctica profesional en las que la pasión y conocimiento de la materia se convierten en los aspectos tácitos y espontáneos que permitan confiar en su estilo de enseñanza. La D1 señala que: 
Los procesos de enseñanza y aprendizaje implican no sólo aspectos cognitivos, sino también está relacionado con cuestiones afectivas, pues "llevarse bien con los grupos" permite solucionar problemas de todo tipo; de integración, académicos incluso personales.

Debido a que la tarea docente es compleja, asume el D7, requiere una planeación y preparación rigurosa. Después de verse a sí mismo como un espejo, aceptó que en algunas ocasiones, cuando el contenido de la unidad temática es muy técnico y extenso, utiliza la técnica expositiva con diapositivas, por su comodidad. Pese a su estilo directivo, considera que debe diseñar actividades como el análisis de casos y su propia experiencia clínica, de tal forma que los alumnos comprendan los objetivos y propósitos de cada actividad, además de desarrollar habilidades metacognitivas y de solución de problemas.

En las reflexiones que hace el D6 cuando observa la videograbación que se le hizo de su clase, menciona sentirse angustiado por el manejo del tiempo; por lo que reconoce que el tono de su voz suena muy apresurado y en ocasiones poco claro en su dicción, lo que, señala él, probablemente obstaculice el entendimiento de los temas que expone a sus alumnos; no obstante, reconoce tener mucha experiencia en el área de las clases que imparte, lo que motiva mucho la asistencia y participación de los alumnos a sus clases, y él considera que ésa es una fortaleza muy importante en su práctica docente. Finalmente, indica que tiene un gran interés por formarse en la docencia.

\section{Discusión}

De acuerdo con los propósitos generales y específicos de este estudio, cabe mencionar que durante la entrevista con algunos profesores fue necesario guiar el análisis de sus videos hacia la definición de metas y estrategias para modificar y/o transformar la práctica docente; mientras que otros recordaron y describieron la secuencia didáctica que siguen, identificaron casi automá- 
ticamente sus fortalezas y debilidades en su quehacer cotidiano. Esta característica corrobora lo que Díaz-Barriga (2002) menciona acerca de que la reflexión no es un fin en sí mismo ni una técnica puntual; tampoco puede ser independiente de los contenidos sobre los que el profesor reflexiona; en todo caso, está condicionada por la finalidad que se persigue, por la orientación que tiene y por el nivel de profundidad que se propicia.

Al respecto, Perrenoud (2007) señala que en un paradigma mediacional de la formación docente, la investigación-acción, la investigación-formación, la innovación, el asesoramiento o la reflexión es ya algo fundamental dentro de la práctica docente. De esta forma, el análisis de dicha práctica, el trabajo sobre el "habitus" y el trabajo por situaciones problema, son dispositivos de formación que tienen por objetivo desarrollar una enseñanza como un docente reflexivo.

Finalmente, y a partir de los resultados obtenidos en este trabajo, se puede concluir que un rasgo que permite aseverar el proceso reflexivo en los docentes es su preocupación por el contenido temático de su materia o por las habilidades básicas que tienen que desarrollar los alumnos para aprender significativamente. Tratan de buscar la forma en que se podría lograr esto, diseñar e idear nuevas estrategias de enseñanza de acuerdo con los intereses de los alumnos y sus propias experiencias personales.

Otro aspecto importante para considerar de los resultados obtenidos con este trabajo es que para continuar con los estudios que promuevan la práctica reflexiva es necesario insistir en que las instituciones de educación superior deben crear espacios académicos que posibiliten la reflexión, interacción y análisis de las experiencias pedagógicas de los docentes, así como impulsar programas permanentes de formación que incluyan talleres o cursos derivados de la propia experiencia como profesionales de la enseñanza. 


\section{Referencias}

Aparicio, J.A. y Pozo, J.I. (2006). De fotógrafos a directores de orquesta: las metáforas desde las que los profesores conciben el aprendizaje. En J.I. Pozo, N. Scheuer, M.P. Pérez, M. Mateos, E. Martín, M. de la Cruz. (Eds.). Nuevas formas de pensar la enseñanza y el aprendizaje (323-340). BarceIona: Graó.

Bain, K. (2007). Lo que hacen los mejores profesores de universidad ( $2^{\mathrm{a}}$ Ed.). España: Publicaciones de la Universidad de Valencia.

Contreras, J. (2001). La autonomía del profesorado. Madrid: Morata.

Díaz-Barriga, F. (2002). Aportaciones de las perspectivas constructivista y reflexiva en la formación docente en el bachiIlerato. Perfiles Educativos, 24(97-98), 6-25.

Marcelo, C. (2008). El profesorado principiante: inserción a la docencia. Barcelona: Octaedro.

Perrenoud, P. (2007). Desarrollar la práctica reflexiva en el oficio de enseñar. Barcelona: Graó.

Schön, D.A. (1983). The reflective practitioner. How professionals think in action. Londres: Temple Smith.

Stenhouse, L. (1985). El profesor como tema de investigación y desarrollo. Revista de Educación, 277, 43-53.

Tardif, M. (2004). Los saberes docentes y su desarrollo profesional. Madrid: Narcea. 